\title{
Inductance Calculation of Tooth-Coil Permanent-Magnet Synchronous Machines
}

\author{
Pavel Ponomarev, Member, IEEE, Yulia Alexandrova, Ilya Petrov, Pia Lindh, Member, IEEE, \\ Elena Lomonova, Senior Member, IEEE, and Juha Pyrhönen, Member, IEEE
}

\begin{abstract}
Analytical calculation methods for all the major components of the synchronous inductance of tooth-coil permanentmagnet synchronous machines are reevaluated in this paper. The inductance estimation is different in the tooth-coil machine compared with the one in the traditional rotating field winding machine. The accuracy of the analytical torque calculation highly depends on the estimated synchronous inductance. Despite powerful finite element method (FEM) tools, an accurate and fast analytical method is required at an early design stage to find an initial machine design structure with the desired performance. The results of the analytical inductance calculation are verified and assessed in terms of accuracy with the FEM simulation results and with the prototype measurement results.
\end{abstract}

Index Terms-Fractional slot winding, inductance calculation, leakage inductance, permanent-magnet synchronous machine (PMSM), tooth coil.

\section{INTRODUCTION}

$\mathbf{F}$ RACTIONAL-SLOT concentrated nonoverlapping winding permanent-magnet synchronous machines (PMSMs) have become very popular over the last two decades [1]. They are nowadays used, for instance, in electrical hybrid vehicles and in ships as propulsion motors, in industry as low-speed direct-drive machines, and in wind energy applications as generators.

The term "fractional-slot nonoverlapping concentrated winding" is very long. Therefore, several shorter descriptions have been used in the literature, such as "concentrated winding" [2], [3], "nonoverlapping winding," [4], [5] or, most popularly, "fractional-slot winding" [1], [6]. All these condensed terms leave room for uncertainty in the description of fractionalslot nonoverlapping concentrated-winding permanent magnet machines with the number of slots per pole and phase $q \leq 0.5$.

The most popular definition "fractional-slot winding" leads to a confusion as the winding may be a fractional-slot one also with $q>1$ (e.g., $q=2.25$ ), which actually refers to a short-pitched distributed-winding machine [7, p. 105]. The term "concentrated winding" refers to a salient pole winding with one slot per pole (IEC 60050-411-37-18) and can be also

Manuscript received August 15, 2013; revised December 5, 2013; accepted January 10, 2014. Date of publication February 6, 2014; date of current version June 6, 2014.

P. Ponomarev, Y. Alexandrova, I. Petrov, P. Lindh, and J. Pyrhönen are with the Laboratory of Electrical Drives Technology, Lappeenranta University of Technology, 53850 Lappeenranta, Finland.

E. Lomonova is with the Department of Electrical Engineering, Eindhoven University of Technology, 5600 Eindhoven, The Netherlands (e-mail: pavel.ponomarev@lut.fi).

Color versions of one or more of the figures in this paper are available online at http://ieeexplore.iee.org.

Digital Object Identifier 10.1109/TIE.2014.2304933 easily mixed up with a distributed "concentric" winding (as an alternative to a diamond winding [7, p. 54]). The most felicitous definition "nonoverlapping winding" can also refer to a distributed integral-slot concentric winding with nonoverlapping coil ends of a single phase [7, p. 53].

In order to avoid such a confusion, the authors have adopted the term "tooth-coil (TC) winding" from [8] and [9] to refer to multiphase machines with fractional-slot concentrated nonoverlapping windings with the number of slots per pole and phase $q \leq 0.5$. This definition is very descriptive as the key feature of these machines is the very compact armature winding that comprises coils around each tooth or every second tooth.

The performance of a PMSM is strongly dependent on the synchronous inductance $L_{s}$, as can be seen from the equation of the maximum (pull-out) torque $T_{\max }$ of a nonsalient pole machine, i.e.,

$$
T_{\max }=\frac{p m E_{\mathrm{PM}} U_{\mathrm{ph}}}{\omega^{2} L_{s}}
$$

where $p$ is the number of pole pairs, $m$ is the number of phases, $E_{\mathrm{PM}}$ is the back electromotive force, $U_{\mathrm{ph}}$ is the phase voltage, and $\omega$ is the electrical angular speed.

An analytical inductance model is required to construct an initial design, which can later on be enhanced and refined by finite element method (FEM) modeling in order to tailor the desired performance for a particular application.

The synchronous inductance $L_{s}$ of a nonskewed PMSM is analytically calculated as a sum of partial inductances, i.e.,

$$
L_{s}=L_{m}+L_{\sigma}=L_{m}+L_{\mathrm{ew}}+L_{u}+L_{\mathrm{tt}}+L_{h}
$$

where $L_{m}$ is the magnetizing inductance, $L_{\sigma}$ is the total leakage inductance, $L_{\mathrm{ew}}$ is the end-winding leakage inductance, $L_{u}$ is the slot leakage inductance, $L_{\mathrm{tt}}$ is the tooth-tip leakage inductance, and $L_{h}$ is the air-gap harmonic leakage inductance.

The air-gap harmonic leakage inductance $L_{h}$ and the magnetizing inductance $L_{m}$ together comprise the air-gap inductance component $L_{\delta}$ [10]. The term "harmonic" is added to the definition of $L_{h}$ in order to emphasize that this inductance component is caused by the leakage flux in the air gap produced only by the asynchronous current linkage harmonics and does not include the air-gap component of the leakage flux of the tooth-tip leakage.

The term "current linkage" denoted by $\Theta$ is used throughout this paper instead of magnetomotive force $F$. This is in accordance with the IEC standards when referring to the surface integral of the current density $J$ produced by the winding currents in the air gap. The current linkage $\Theta$ (and the 
magnetomotive force $F$ ) is measured, according to the International System of Units, in amperes and not in "ampere-turns" [11]. In analytic calculations, the current linkage $\Theta$ is normally calculated per pole, resulting in the amplitude exciting half of the closed magnetic circuit and, therefore, being also half of the magnetomotive force of the circuit.

In previous works, several models have been considered for the calculation of the synchronous inductance; nevertheless, these models are somewhat incomplete. In [4], the tooth-tip leakage inductance component was omitted from the analysis. In [12], the end-winding leakage inductance and the tooth-tip leakage inductance components were specified using traditional equations applied to the design of integral-slot machines. It is shown that the equations applied in this paper improve the analysis and give accurate results for the inductances of TC-PMSMs.

Many of the previous works do not distinguish $L_{h}$ and $L_{m}$ in the air gap, but in these works, the terms "phase self-inductance" $L_{U}$ (which is equivalent to the air-gap inductance $L_{\delta}$ ) and "phase mutual inductance" $M_{\mathrm{UV}}$ are used instead [12]. In this paper, the synchronous inductance is derived by separating the magnetizing inductance (torque-producing component) and the harmonic leakage inductance in the air gap. Without such a distinction, it is difficult to analytically compare TC-PMSMs with various slot/pole combinations with each other as $L_{h}$ plays a significant role in the behavior of the TC-PMSMs [13].

The main objective of this paper is to present a complete analytical inductance model for the TC-PMSMs. This paper elaborates the inductance calculation of TC-PMSMs by reevaluating the existing analytical approaches for all the major components of the synchronous inductance, taking into account the particular features of the TC-PMSMs. Furthermore, the rationale of the selection of the particular equations is presented. The analytical results are compared with the FEM analysis results and the experimental measurements.

Section II introduces the analytical evaluation of all the main inductance components of the synchronous inductance for a TC-PMSM. An equation for the magnetizing inductance $L_{m}$ is derived. Furthermore, a mutual coupling factor between the phases $m_{c}$ is determined, as a low value of the mutual coupling factor is important, for instance, in the design of fault-tolerant drives. Moreover, analytical equations for all the leakage components are listed. Then, a table to enable a comparison of TC-PMSMs with different slot/pole combinations is given.

Section III investigates the role of synchronous inductance in the torque production of a TC-PMSM. Methods to increase the torque capabilities are discussed.

Section IV summarizes the experimental verification of the proposed inductance model. Several double-layer TC-PMSMs with 18/16, 12/10, and 24/16 (slots/poles) are given as examples.

\section{InduCtance CALCUlation}

Here, accurate analytical equations for each component of $L_{s}$ are discussed.

\section{A. Magnetizing Inductance}

The main inductance of a phase of the stator winding $L_{\mathrm{sp}}$ is calculated by taking the approach in [7] as follows. The

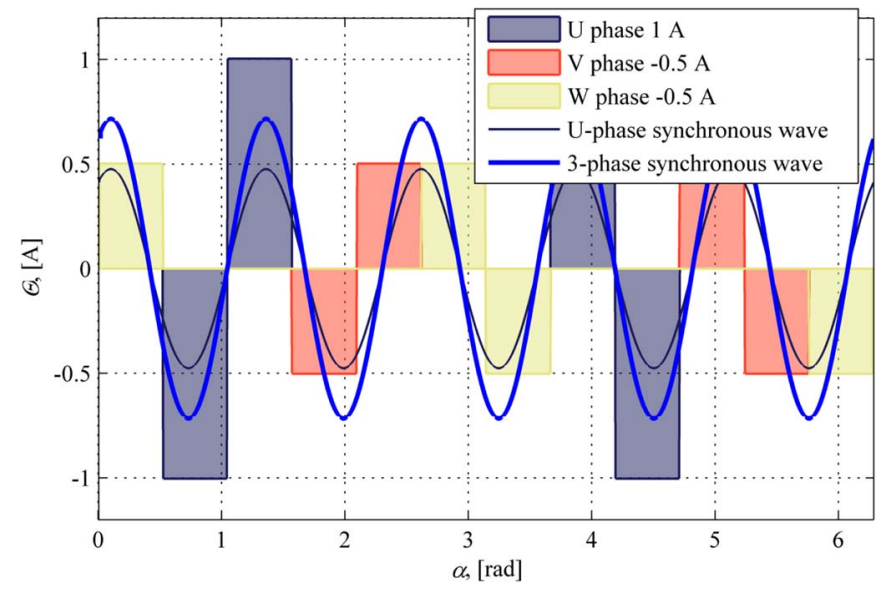

Fig. 1. Current linkage waveforms of a 12/10 TC-PMSM produced by the stator winding when the phase $\mathrm{U}$ carries its peak current. Although the mutual inductance seems negligible, also the phases $\mathrm{V}$ and $\mathrm{W}$ contribute to the synchronous current linkage harmonic in the TC machine resulting in a similar magnetizing inductance as in integral-slot machines.

main stator flux linkage $\Psi_{\mathrm{sp}}$ (the flux linkage produced by the working harmonic of the stator single-phase current linkage) is generated by the U-phase stator current $I_{s}$ and the main inductance $L_{\mathrm{sp}}$ when the other phases are nonexcited. Therefore, the single-phase main inductance can be expressed by using the peak values of the sinusoidal flux linkage and the sinusoidal phase current as

$$
L_{\mathrm{sp}}=\frac{\hat{\Psi}_{\mathrm{sp}}}{\hat{I}_{s}}
$$

The synchronous component of the air-gap flux density $B_{\mathrm{sp}}$ is sinusoidally distributed along the air gap. The peak value of the flux linkage $\Psi_{\mathrm{sp}}$ can, therefore, be expressed as

$$
\hat{\Psi}_{\mathrm{sp}}=k_{\mathrm{wp}} N_{s} \frac{2}{\pi} \tau_{p} l^{\prime} \hat{B}_{\mathrm{sp}}
$$

where $\tau_{p}$ is the pole pitch, $l^{\prime}$ is the effective stator core length [14], [15], $N_{s}$ is the number of phase turns in series, $k_{\mathrm{wp}}$ is the winding factor of the synchronous (operating) current linkage harmonic, the factor $2 / \pi$ is the arithmetic per unit (p.u.) average value of a sinusoidal half-wave, and $\hat{B}_{\mathrm{sp}}$ is the peak value of the sinusoidal flux density in the air gap.

The synchronous component of the air-gap flux density $B_{\mathrm{sp}}$ produced by the stator current linkage $\Theta_{\mathrm{sp}}$ (see Fig. 1) is

$$
\hat{B}_{\mathrm{sp}}=\mu_{0} \frac{\hat{\Theta}_{\mathrm{sp}}}{\delta_{\mathrm{ef}}}=\frac{\mu_{0}}{\delta_{\mathrm{ef}}} \frac{4 q}{\pi} \frac{z_{Q}}{c} k_{\mathrm{wp}} \hat{I}_{s}
$$

where $\mu_{0}$ is the permeability of vacuum $\left(4 \cdot \pi \cdot 10^{-7} \mathrm{~V} \cdot \mathrm{s} /(\mathrm{A}\right.$. $\mathrm{m})), \delta_{\text {ef }}$ is the effective air gap met by the stator synchronous current linkage component, $q$ is the number of stator slots per pole and phase, $z_{Q}$ is the number of stator conductors in a slot, the factor $c=1$ is for single-layer windings, and the factor $c=$ 2 is for double-layer windings. In the following, only doublelayer windings are considered for simplicity. For double-layer windings, (5) can be rewritten as

$$
\hat{B}_{\mathrm{sp}}=\frac{\mu_{0}}{\delta_{\mathrm{ef}}} \frac{4 q}{\pi} \frac{m}{Q_{s}} k_{\mathrm{wp}} N_{s} \hat{I}_{s}
$$


where $m$ is the number of phases, and $Q_{s}$ is the number of stator slots.

Combining (3), (4), and (6), the phase inductance can be found, i.e.,

$$
L_{\mathrm{sp}}=\frac{2}{\pi} \tau_{p} l^{\prime} \frac{\mu_{0}}{\delta_{\mathrm{ef}}} \frac{4 q}{\pi} \frac{m}{Q_{s}}\left(k_{\mathrm{wp}} N_{s}\right)^{2} .
$$

The effective air gap $\delta_{\text {ef }}$ takes into account the magnetic voltage drops in the air gap (increased by the Carter factor [16]), in the stator teeth, in the permanent magnets, and in the rotor and stator yokes. The iron saturation effect should be also included here.

The magnetizing inductance $L_{m}$ of an integral-slot rotating field winding is determined by multiplying (7) by a factor $m / 2$ [7] that is due to the mutual inductance between the phases as the resultant current linkage wave is produced by all the $m$ phases of the machine together, i.e.,

$$
L_{m}=\frac{m}{2} L_{\mathrm{sp}}=\tau_{p} l^{\prime} \frac{\mu_{0}}{\delta_{\mathrm{ef}}} \frac{4 q}{Q_{s}}\left(\frac{m}{\pi} k_{\mathrm{wp}} N_{s}\right)^{2} .
$$

Fig. 1 shows how the synchronous harmonic magnitude increases by a factor of $m / 2$ also in a TC machine when the effects of all the three phases are taken into account. This happens although the real mutual coupling is low or almost nonexistent. Therefore, the magnetizing inductance of TC machines is calculated analogously to integral-slot machines, although the mutual inductance between the phases can be zero as in the case with the $12 / 10$ machine.

\section{B. Mutual Inductance Between Phases}

The mutual inductance in TC machines behaves in a significantly more complicated way than in machines with integralslot windings. For example, in a three-phase 12/10 machine, there is no V- or W-phase current linkage that could produce additional magnetic fluxes through the first phase winding (U). Fig. 1 illustrates how there are no sectors along the stator bore where the current linkages of different phases should interact. This justifies the use of a 12/10 machine as a faulttolerant machine with magnetically decoupled phases and even provides an opportunity to build modular segmented stators with physically separate phase coil sections. Other machines having sectors of even numbers of adjacent coils of the same phase can be also built as modular machines, for instance, 12/14 or $24 / 20$.

There are also other TC-PMSM topologies where the interaction between the current linkages of different phases is more complex. For example, an 18/16 machine has the current linkage waveforms of two phases, as illustrated in Fig. 2. In some sectors, the fluxes of different phases are summed up, but in other sectors, the fluxes weaken each other. Therefore, the mutual coupling factor $m_{c}$ should be calculated as [10]

$$
m_{c}=\frac{M_{\mathrm{UV}}}{L_{U}}=\frac{\int_{0}^{2 \pi} \Theta_{U} \Theta_{V} d \alpha}{\int_{0}^{2 \pi} \Theta_{U} \Theta_{U} d \alpha} .
$$

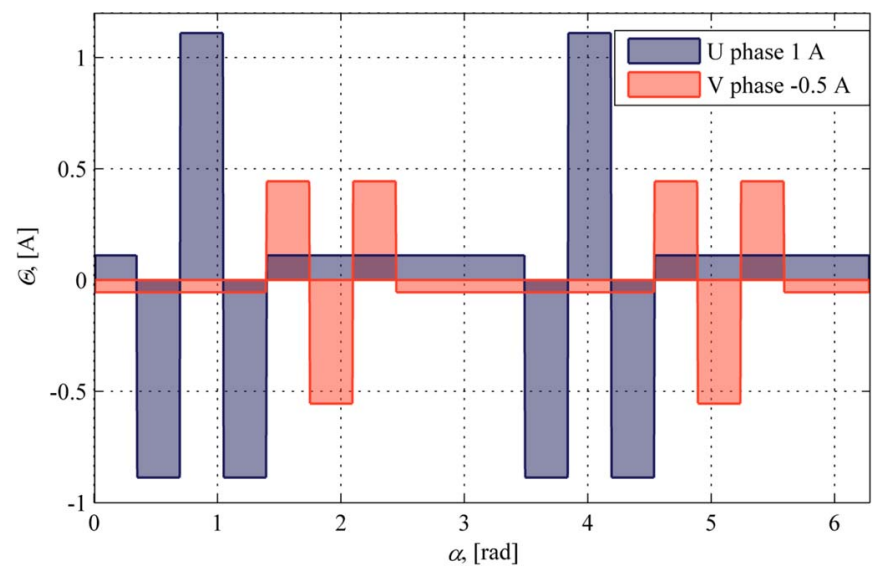

Fig. 2. Current linkage waveforms of two phases of an 18/16 TC-PMSM.

\begin{tabular}{|c|c|c|c|c|c|c|c|c|c|c|}
\hline & $2 p$ & 4 & 6 & 8 & 10 & 12 & 14 & 16 & 18 & 20 \\
\hline & $q$ & $1 / 2$ & & $1 / 4$ & $1 / 5$ & & $1 / 7$ & $1 / 8$ & & $1 / 10$ \\
\hline & $k_{\mathrm{wp}}$ & 0.866 & & 0.866 & 0.5 & & 0.5 & 0.866 & & 0.866 \\
\hline 0 & $m_{\mathrm{c}}$ & -0.5 & & -0.5 & 0 & & 0 & -0.5 & & -0.5 \\
\hline & $\sigma_{\delta}$ & 0.46 & & 4.8 & 26 & & 53 & 22 & & 36 \\
\hline & $q$ & $3 / 4$ & $1 / 2$ & $3 / 8$ & $3 / 10$ & $1 / 4$ & $3 / 14$ & $3 / 16$ & & $3 / 20$ \\
\hline 0 & $k_{\mathrm{wp}}$ & & 0.866 & 0.945 & 0.945 & 0.866 & 0.617 & 0.328 & & 0.328 \\
\hline 9 & $m_{\mathrm{c}}$ & & -0.5 & -0.039 & -0.039 & -0.5 & -0.039 & -0.039 & & -0.039 \\
\hline & $\sigma_{\delta}$ & & 0.46 & 1.2 & 2.4 & 4.8 & 15 & 71 & & 112 \\
\hline & $q$ & 1 & $2 / 3$ & $1 / 2$ & $2 / 5$ & & $2 / 7$ & $1 / 4$ & & $1 / 5$ \\
\hline 12 & $k_{\mathrm{wp}}$ & & & 0.866 & 0.933 & & 0.933 & 0.866 & & 0.5 \\
\hline & $m_{\mathrm{c}}$ & & & -0.5 & 0 & & 0 & -0.5 & & 0 \\
\hline & $\sigma_{\delta}$ & & & 0.46 & 0.96 & & 2.9 & 4.8 & & 26 \\
\hline & $q$ & $11^{1 / 4}$ & $5 / 6$ & $5 / 8$ & $1 / 2$ & & $5 / 14$ & $5 / 16$ & & $1 / 4$ \\
\hline 15 & $k_{\mathrm{wp}}$ & & & & 0.866 & & 0.951 & 0.951 & & 0.866 \\
\hline & $m_{\mathrm{c}}$ & & & & -0.5 & & -0.013 & -0.013 & & -0.5 \\
\hline & $\sigma_{\delta}$ & & & & 0.46 & & 1.4 & 2.1 & & 4.8 \\
\hline & $q$ & $11^{1 / 2}$ & 1 & $3 / 4$ & $3 / 5$ & $1 / 2$ & $3 / 7$ & $3 / 8$ & & $3 / 10$ \\
\hline 18 & $k_{\mathrm{wp}}$ & & & & & 0.866 & 0.902 & 0.945 & & 0.945 \\
\hline & $m_{\mathrm{C}}$ & & & & & -0.5 & 0 & -0.039 & & -0.039 \\
\hline & $\sigma_{\delta}$ & & & & & \begin{tabular}{|l|}
0.46 \\
\end{tabular} & 0.83 & 1.2 & & 2.4 \\
\hline & $q$ & $13 / 4$ & $1^{1 / 6}$ & $7 / 8$ & $7 / 10$ & $7 / 12$ & $1 / 2$ & $7 / 16$ & & $7 / 20$ \\
\hline 21 & $k_{\mathrm{wp}}$ & & & & & & 0.866 & 0.89 & & 0.953 \\
\hline & $m_{\mathrm{C}}$ & & & & & & -0.5 & -0.007 & & -0.007 \\
\hline & $\sigma_{\delta}$ & & & & & & 0.46 & 0.8 & & 1.5 \\
\hline & $q$ & 2 & $1^{1} / 3$ & 1 & $4 / 5$ & $2 / 3$ & $4 / 7$ & $1 / 2$ & & $2 / 5$ \\
\hline 24 & $k_{\mathrm{wp}}$ & & & & & & & 0.866 & & 0.933 \\
\hline & $m_{\mathrm{c}}$ & & & & & & & -0.5 & & 0 \\
\hline & $\sigma_{\delta}$ & & & & & & & 0.46 & & 0.96 \\
\hline & & $2^{3} / 4$ & $1^{1} / 2$ & $13 / 8$ & $9 / 10$ & $3 / 4$ & $9 / 14$ & $9 / 16$ & $1 / 2$ & $9 / 20$ \\
\hline 27 & $k_{\mathrm{wp}}$ & & & & & & & & 0.866 & 0.877 \\
\hline 21 & $m_{\mathrm{C}}$ & & & & & & & & -0.5 & -0.004 \\
\hline & $\sigma_{\delta}$ & & & & & & & & $\begin{array}{l}0.46 \\
\end{array}$ & \begin{tabular}{|l|}
0.75 \\
\end{tabular} \\
\hline
\end{tabular}

TABLE I

HARMONIC AIR GAP LEAKAGE FACTORS Of TC-PMSMs

For integral-slot three-phase machines with essentially sinusoidal air-gap flux density, this factor is $m_{c}=-0.5$ [10]. For an 18/16 machine, the mutual coupling coefficient is $m_{c}=$ -0.0385 . A $12 / 10$ machine has $m_{c}=0$. Calculated mutual coupling coefficients $m_{c}$ for different slot/pole combinations of TC-PMSMs are shown in Table I. A low value of $m_{c}$ indicates a low magnetic coupling between the phases, which is beneficial from a machine's fault tolerance point of view. 
If a fault occurs in one phase of a machine with $m_{c}=0$, the magnetic flux densities in magnetic circuits of other phases will not be considerably influenced.

Although the mutual coupling $m_{c}$ can be zero, it does not influence the equation of the magnetizing inductance (8). All the three phases contribute together to the magnetizing inductance (as shown in Fig. 1) even without air-gap interaction with each other, which is a distinctive feature of TC-PMSMs.

Table I only takes into account the mutual coupling $m_{c}$ caused by the air-gap flux. Nevertheless, there are other magnetic couplings between the phases, namely, a coupling caused by the slot leakage flux and a coupling that is due to the endwinding leakage flux. The mutual coupling by the end-winding leakage flux is relatively weak in the TC-PMSMs as the end windings are compact, and different phases are usually coupled only through the air. The slot leakage mutual coupling, however, is strong when the coil sides of different phases are located in the same slot. This coupling is much more important and can make up to $50 \%$ of the total phase slot leakage inductance [12], [17] depending on the geometry and the winding layout.

\section{Air-Gap Harmonic Leakage Inductance}

Owing to the discrete nature of the TC windings, the current linkage generated by such a winding produces a very nonsinusoidal current linkage waveform in the air gap. This waveform contains a large proportion of current linkage harmonics, which produce harmonic magnetic fluxes [13]. These fluxes do not participate in the production of useful torque yet increase the armature reaction in the windings and thereby contribute to the leakage inductance. Additional eddy-current losses in the rotor are also generated [18]. The air-gap harmonic leakage inductance $L_{h}$ can be defined as

$$
L_{h}=\sigma_{\delta} L_{m}
$$

where $\sigma_{\delta}$ is the harmonic air-gap leakage factor [8], [13], i.e.,

$$
\sigma_{\delta}=\sum_{\substack{v=1 \\ v \neq p}}^{v=+\infty}\left(p \cdot \frac{k_{\mathrm{wv}}}{v \cdot k_{\mathrm{wp}}}\right)^{2}
$$

where $k_{\mathrm{wv}}$ is the winding factor of the $v$ th spatial harmonic [13], [19]. The term $v=p$ represents the synchronous harmonic and, thus, the magnetizing inductance $L_{m}$ component.

In TC machines, the highly distorted air-gap flux density strongly contributes to the air-gap harmonic leakage inductance. Possible subharmonic flux barriers in the stator and rotor, the slot openings, and the air-gap height can alter the spectrum of the air-gap flux density waveform and, thus, also the harmonic air-gap leakage factor, thereby influencing the rotor losses and torque [20]-[22].

Table I shows the calculated air-gap harmonic leakage factors $\sigma_{\delta}$ for different slot/pole combinations of TC-PMSMs. In addition, for these combinations, the numbers of slots per pole and phase $q$, the winding factors of synchronous harmonics $k_{\mathrm{wv}}$, and the mutual coupling coefficients $m_{c}$ are given.

As the magnetizing inductance $L_{m}$ is a result of the current linkages of all the three phases, in a three-phase system, all

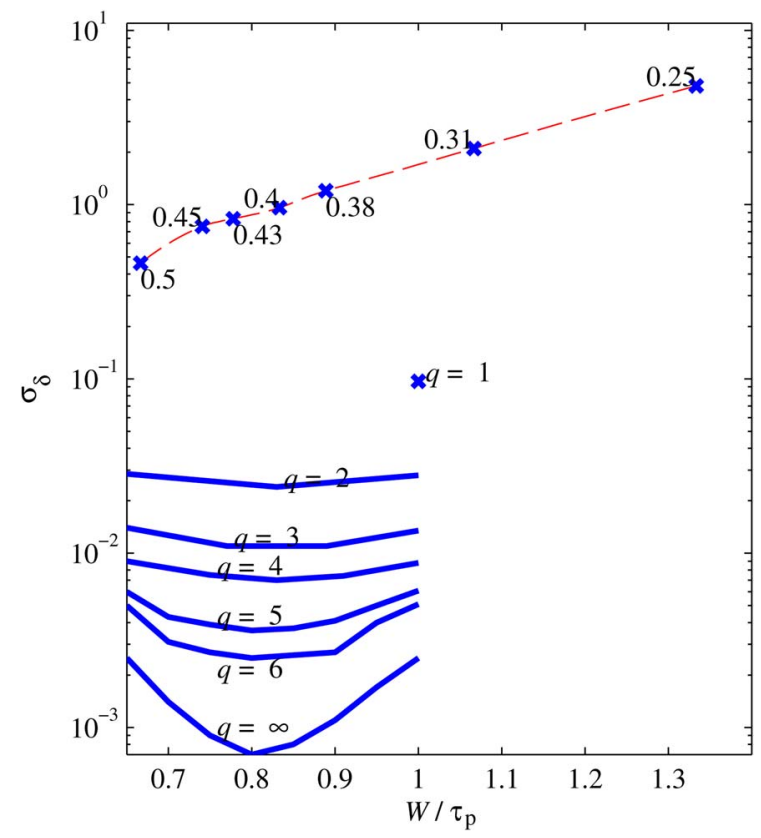

Fig. 3. Air-gap harmonic leakage factors $\sigma_{\delta}$ for integer-slot and TC winding machines versus the coil span $W$ over the pole pitch $\tau_{p}$ (for TC windings, $W$ is equal to slot pitch $\tau_{u}$ ).

third-order harmonics are excluded from the computation. In [13], the air-gap harmonic leakage coefficients $\sigma_{\delta}$ were erroneously calculated for single-phase current linkage waveforms taking into account the third-order harmonics. In Table I, this mistake is corrected.

Table I enables the comparison of different TC-PMSMs. Combinations with higher air-gap harmonic leakage factors $\sigma_{\delta}$ have higher leakage inductances and, usually, also larger field weakening regions, but lower maximum torque at nominal speed (assuming that they have the same voltage limit).

A higher air-gap harmonic leakage factor may also indicate a higher amount of rotor losses resulting from asynchronous current linkage harmonics. Combinations with a very high $\sigma_{\delta}$ are not feasible at all, as their torque production is considerably limited by very high leakage inductances.

Fig. 3 shows that the trend specific for integral-slot machines [23] - machines with lower $q$ have higher air-gap harmonic leakage factors $\sigma_{\delta}$-is also valid for TC-PMSMs. However, in TC-PMSMs, the air-gap harmonic leakage factors $\sigma_{\delta}$ are significantly higher.

\section{End-Winding Leakage Inductance}

The end-winding leakage flux generally flows around the end-winding conductors through air. It can also flow through steel clamp rings, parts of the frame, or through the end laminations of the stator. Fig. 4 shows possible flux paths of the end-winding leakage.

The end-winding leakage inductance is a 3-D phenomenon. It requires a considerable effort to make a 3-D FEM model to accurately evaluate this leakage component. Solid parts having eddy currents also affect the paths of the magnetic fluxes and, thereby, the leakage inductance. Other leakage inductance components can be quite accurately evaluated by applying 2-D FEM machine models. 


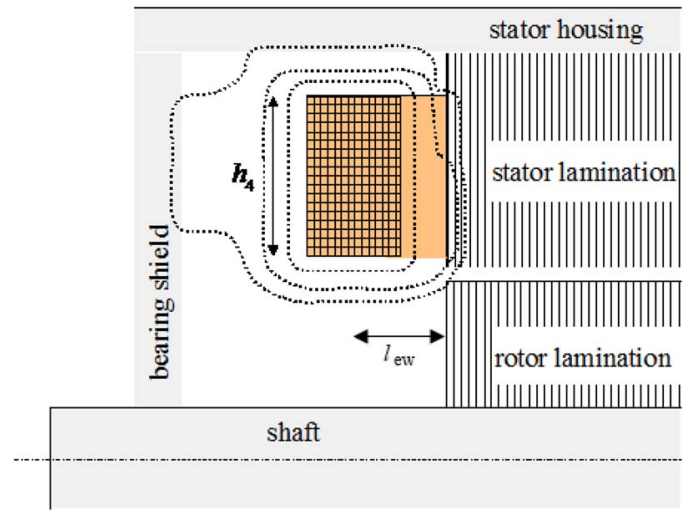

Fig. 4. End-winding leakage flux paths.

There are many empirical and analytical models to calculate the end-winding leakage inductances. However, these models give quite different results. Most of these models are developed for integral-slot distributed windings. For example, an empirical analytical model for calculating the end-winding leakage inductance $L_{\text {ew }}$ is described in [7], i.e.,

$$
L_{\text {ew }}=\frac{4 m}{Q_{s}} \mu_{0} N_{s}^{2} q l_{w} \lambda_{\text {ew }}
$$

where $q$ is the number of slots per pole and phase, $l_{w}$ is the average length of the end winding, and $\lambda_{\text {ew }}$ is the end-winding leakage permeance factor, i.e.,

$$
\lambda_{\mathrm{ew}}=\frac{2 l_{\mathrm{ew}} \lambda_{h}+w_{\mathrm{ew}} \lambda_{w}}{l_{w}}
$$

where $l_{\text {ew }}$ is the axial length of the end winding measured from the end of the stack, $\lambda_{h}$ is the empirical axial permeance factor, $w_{\text {ew }}$ is the coil span, and $\lambda_{w}$ is the empirical span permeance factor of the end winding.

The end-winding permeance factor $\lambda_{\mathrm{ew}}$ is usually determined relying on empirical values defined for various shapes of distributed end windings [7], [23], [24]. However, there are no end-winding permeance coefficients available for TC windings in the literature.

There is, however, a simple approach that can be used instead. In this approach, the end-winding sections of a TC-PMSM around the tooth can be considered halves of a solenoid. The end-winding leakage inductance of TC windings can be calculated by using an expression for an air-cored solenoid inductance, i.e.,

$$
L_{\mathrm{sol}}=\mu_{0} \mu_{\mathrm{env}} \frac{\left(\frac{z_{Q}}{c}\right)^{2} S}{h_{4}}
$$

where $h_{4}$ is the height of the solenoid, $S$ is the cross-sectional area, and $\mu_{\mathrm{env}}$ is the relative permeability of the environment. Therefore, if the end turns are made as half-circles $\left(l_{\mathrm{ew}}=\right.$ $w_{\text {ew }} / 2$ ), the total inductance of the end windings of a doublelayer winding can be expressed as

$$
L_{\mathrm{ew}}=\frac{Q_{s}}{m} L_{\mathrm{sol}}=\mu_{0} \mu_{\mathrm{env}} \frac{Q_{s}}{m} \frac{\left(\frac{z_{Q}}{2}\right)^{2} \pi l_{\mathrm{ew}}^{2}}{h_{4}} .
$$

The relative permeability $\mu_{\mathrm{env}}$ of air is 1 . Nevertheless, because of the presence of iron parts in the vicinity (iron frame,
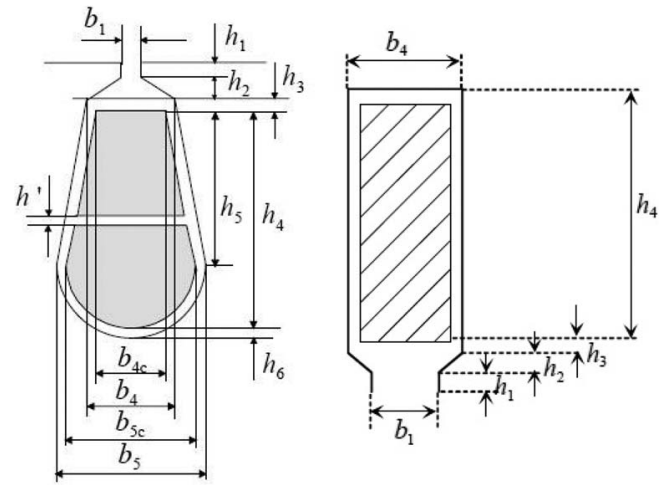

Fig. 5. Slot dimensions.

end laminations of the stator stack), this factor can be chosen from the range of 1.2-2 depending on the materials and the compactness of the assembly of the machine end regions.

In [25], a more complex analytical empirical equation for evaluating the end-winding inductance is developed for TC windings. This equation takes into account the geometry of the end windings and the material of the core. A good correlation between the 3-D-FEM and the proposed method is found.

There is also a mutual coupling between the phases caused by the end-winding mutual inductance. Nevertheless, this coupling is very weak and can therefore be neglected without making a significant error [17].

\section{E. Slot Leakage Inductance}

The current flowing inside the slot conductors produces a flux, part of which crosses the air gap, the rest passing across the slot from one tooth to another [see Fig. 6(a) and (b)]. The latter part produces an inductance component $L_{u}$, which is called the slot leakage inductance.

The slot leakage inductance is analytically calculated by

$$
L_{u}=\frac{4 m}{Q_{s}} \mu_{0} N_{s}^{2} l^{\prime} \lambda_{u}
$$

where $\lambda_{u}$ is the slot leakage permeance factor [7], [23], [24], [26].

The slot leakage permeance factor is calculated assuming that the leakage flux passes straight from one side of the slot to the other side crossing the center line of the slot in the orthogonal direction. The parameter $\lambda_{u}$ is calculated using the slot dimensions in Fig. 5. The slot leakage permeance factor for a double-layer winding and horizontally divided layers can be calculated as [7], [10]

$$
\lambda_{u}=k_{1} \frac{h_{4}-h^{\prime}}{3 b_{4}}+k_{2}\left(\frac{h_{3}}{b_{4}}+\frac{h_{1}}{b_{1}}+\frac{h_{2}}{b_{4}-b_{1}} \ln \frac{b_{4}}{b_{1}}\right)+\frac{h^{\prime}}{4 b_{4}}
$$

where the factors $k_{1}$ and $k_{2}$ take into account the mutual inductance when the coils of different phases are present in one slot [17]. Without making a significant error, (17) can be also used for vertically divided layers. The factors $k_{1}$ and $k_{2}$ are calculated as

$$
k_{1}=\frac{5+3 g}{8} \quad k_{2}=\frac{1+g}{2} \quad g=\frac{1}{n_{\mathrm{ps}}} \sum_{n=1}^{n_{\mathrm{ps}}} \cos \gamma_{n}
$$



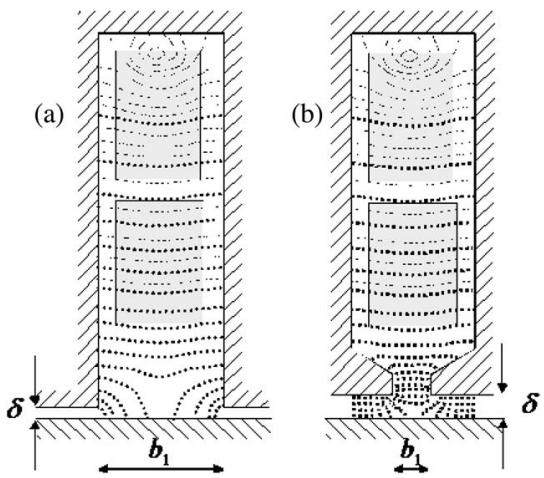

Fig. 6. Slot and tooth-tip leakage flux lines. (a) and (b) Open slot and semiclosed slot with the slot opening $b_{1}$ and the air gap $\delta$, respectively.

where $g$ is the average value of the temporal phase angle variation $\gamma_{n}$ between the coils in the $n_{\mathrm{ps}}$ slots, where the coils of one phase are located. For a 12/10 machine, $g=0.75$, and for a $9 / 8$ machine, $g=0.83$.

The slot leakage inductance is modeled assuming that the leakage flux lines crossing the slot are straight. Nevertheless, this is not completely true, particularly in the region close to the air gap, where the flux lines are bent because of the proximity of the iron parts of the rotor [27]. This fringing flux leakage in the slot close to the air gap can be taken into account by a tooth-tip leakage inductance model.

\section{F. Tooth-Tip Leakage Inductance}

The sum of the slot and tooth-tip leakage inductances is increased when the slot openings are narrow and the air gap is long. Instead, when the air gap is short and the slot openings are wide, as in the case of PMSMs with open slots, the sum of the slot and tooth-tip leakage inductances is decreased, as shown in Fig. 6(a). The flux in the slot bends toward the rotor decreasing the slot leakage.

This change in the slot leakage is taken into account by the tooth-tip leakage inductance $L_{\mathrm{tt}}$. In the case of large $b_{1} / \delta$ (open slots), $L_{\mathrm{tt}}$ can be even negative, making necessary corrections to the slot leakage inductance calculations. Thus

$$
L_{\mathrm{tt}}=\frac{4 m}{Q_{s}} \mu_{0} N_{s}^{2} l^{\prime} k_{2} \lambda_{\mathrm{tt}}
$$

where $\lambda_{\mathrm{tt}}$ is the tooth-tip leakage permeance factor, and $k_{2}$ is a factor that takes into account the presence of different phases in a slot (18).

The permeance factor can be empirically calculated according to Richter and Brüderlink [23] or Müller et al. [24] and Voldek [26] (see Fig. 7). The model of Müller et al. gives better results as it allows negative values of $\lambda_{\mathrm{tt}}$ in the case of open slots and a short air gap. When the slot openings are narrow, $\lambda_{\mathrm{tt}}$ is considerable and positive. However, when the slot openings are wide, $\lambda_{\mathrm{tt}}$ becomes negative. The permeance factor can be calculated according to [24] and [26] as

$$
\lambda_{\mathrm{tt}}=\frac{1}{2 \pi}\left[\ln \left(\frac{\delta^{2}}{b_{1}^{2}}+\frac{1}{4}\right)+4 \frac{\delta}{b_{1}} \arctan \frac{b_{1}}{2 \delta}\right] .
$$

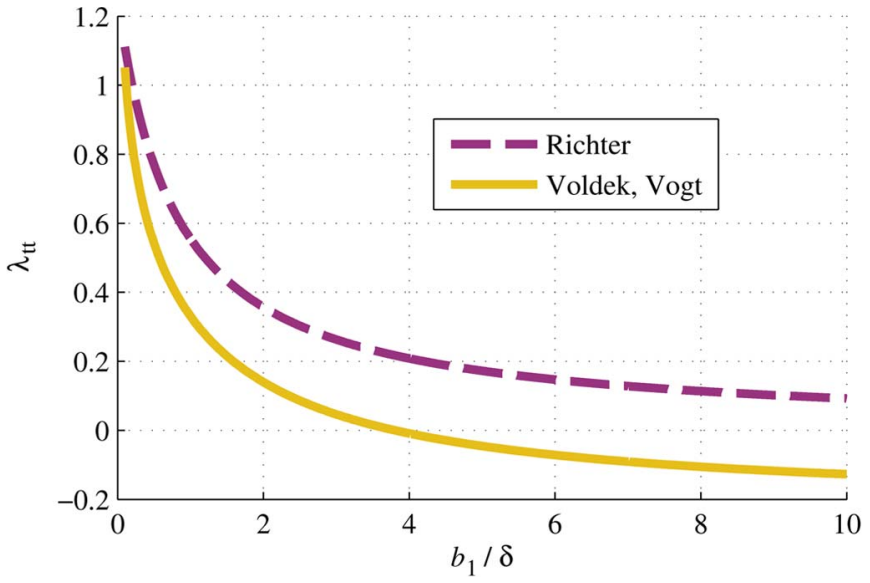

Fig. 7. Permeance factor of the tooth-tip leakage [23], [24], [26].

For surface permanent magnet (SPM) configurations, the airgap length $\delta$ should include the physical air gap and the height of the magnets divided by the relative permeability $h_{\mathrm{PM}} / \mu_{\mathrm{rPM}}$ of the permanent magnet material. For an interior permanent magnet (IPM) configuration, only the physical air gap should be included in the tooth-tip leakage calculation.

\section{MACHINE PERForMANCE}

The maximum torque at a certain speed and voltage depends on the synchronous inductance of the machine. The per-unit equation for the maximum torque $T_{\max }$ of a nonsalient pole PMSM (1) is given in Section I. Combining (1), (2), and (10), we obtain

$$
T_{\max }=\frac{p m E_{\mathrm{PM}} U_{\mathrm{ph}}}{\omega^{2}\left(L_{m}\left(1+\sigma_{\delta}\right)+L_{\mathrm{ew}}+L_{u}+L_{\mathrm{tt}}\right)} .
$$

To reach a large overload capability (potential maximum torque at the rated speed and voltage) of the machine, the synchronous inductance should be small. As $E_{\mathrm{PM}}$ is proportional to $L_{m}$, it is not necessarily feasible to decrease the magnetizing inductance $L_{m}$ when aiming to improve the performance of a machine according to (21). Hence, if the target is to increase the torque production of a machine, the leakage components of the synchronous inductance should rather be decreased. In the following, actions to increase $T_{\max }$ are outlined.

Different TC machines have different air-gap harmonic leakage factors. Therefore, machine topologies with low air-gap harmonic leakage factors should be selected. However, in some cases, such as in traction applications, a high leakage may be needed to obtain a long field-weakening range using a low demagnetizing current. Therefore, a topology with a high air-gap leakage may be advisable. Subharmonic flux barriers should be used to decrease the subharmonic component of the airgap harmonic leakage inductance $L_{h}$. These flux barriers can be used in the rotor construction [21] and, in some cases, also in the stator construction [20]. Furthermore, the flux barriers considerably decrease the core losses. The effect of flux barriers on saliency should be also taken into account when flux barriers are used. 


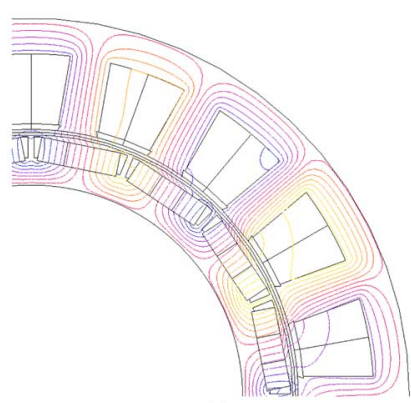

(a)

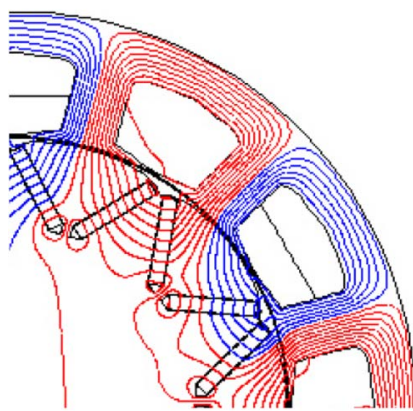

(c)

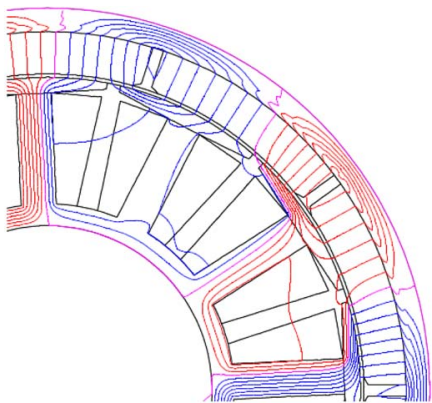

(b)

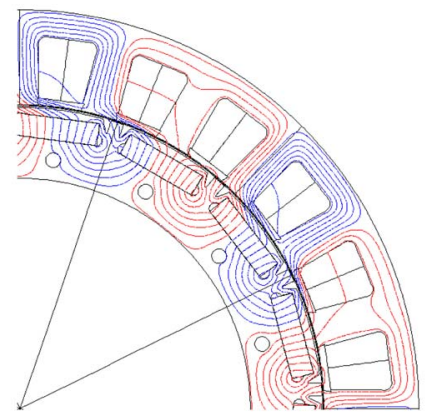

(d)
Fig. 8. Test machine geometries (not in scale). (a) $26 \mathrm{~kW} \mathrm{18/16} \mathrm{IPM.}$ (b) $4.7 \mathrm{~kW} \mathrm{12/10} \mathrm{SPM} \mathrm{outer} \mathrm{solid} \mathrm{rotor.} \mathrm{(c)} 45 \mathrm{~kW} \mathrm{12/10} \mathrm{V-shaped} \mathrm{IPM} \mathrm{with} \mathrm{a}$ complex rotor geometry. (d) $110 \mathrm{~kW} 24 / 16$ IPM.

End-winding leakage inductance $L_{\mathrm{ew}}$ can be decreased if the coils are wound as tight as possible. Clamping rings from stainless steel or other nonmagnetic material should be used for the stack assembly. The frame should be preferably nonmagnetic.

The slot leakage inductance $L_{u}$ can be minimized by avoiding deep slots. To achieve a high torque density, the aspect ratio (height/width) of the slot should be as small as possible (even close to 1 ).

Considering the tooth-tip leakage inductance component $L_{\mathrm{tt}}$, open slots and nonmagnetic wedges should be used. This, however, also affects the magnetizing inductance by increasing the equivalent air gap in the rotor SPM configuration. The height of the air gap can be optimized by the FEM considering its effects on the magnetizing and leakage inductances and core losses.

\section{EXPERIMENTAL RESULTS}

Several radial flux double-layer TC-PMSMs were analytically designed. Their performances were predicted based on the estimated inductances. Then, FEM models were constructed and simulated. After that, prototypes were built, and parameters were measured. The measurement results were also practically supported by the identification run results with ACS M1 converters by $\mathrm{ABB}$. The flux lines of the machines under the loading conditions are depicted in Fig. 8(a)-(d).

Table II shows the analytically estimated inductances for four different TC-PMSMs with the p.u. values in brackets. The p.u. values of the machines are based on the rated voltages, currents, and frequencies of the machines. For the $4.7-\mathrm{kW}$ $12 / 10$ machine, the values of slot and tooth-tip leakage inductances are overestimated, as saturation of the long tooth
TABLE II

Calculated Inductance Components For Four TC-PMSMs

\begin{tabular}{l|c|c|c|c}
\hline Component & $26 \mathrm{~kW} 18 / 16$ & $4.7 \mathrm{~kW} 12 / 10$ & $45 \mathrm{~kW} \mathrm{12/10}$ & $110 \mathrm{~kW} \mathrm{24/16}$ \\
\hline$L_{\mathrm{ew}},[\mathrm{mH}]$ & $0.43(0.10)$ & $0.17(0.01)$ & $0.34(0.03)$ & $0.01(0.01)$ \\
\hline$L_{\mathrm{u}},[\mathrm{mH}]$ & $0.73(0.18)$ & $4.6(0.21)$ & $2.33(0.19)$ & $0.19(0.12)$ \\
\hline$L_{\mathrm{tt}},[\mathrm{mH}]$ & $0.03(0.01)$ & $3.8(0.18)$ & $-0.02(-0.01)$ & $-0.05(-0.03)$ \\
\hline$L_{\mathrm{h}},[\mathrm{mH}]$ & $0.63(0.15)$ & $2.6(0.12)$ & $3.27(0.27)$ & $0.22(0.14)$ \\
\hline$L_{\mathrm{md}},[\mathrm{mH}]$ & $0.53(0.13)$ & $2.8(0.13)$ & $3.41(0.28)$ & $0.44(0.28)$ \\
\hline$L_{\mathrm{sd}},[\mathrm{mH}]$ & $2.34(0.56)$ & $14.0(0.65)$ & $9.33(0.76)$ & $0.82(0.52)$
\end{tabular}

tips is not correctly accounted during analytical calculations. Simultaneously, the air-gap harmonic leakage inductance is overestimated because of the machine's solid nonlaminated rotor construction. Such a solid rotor damps the harmonic fluxes by the induced eddy currents. However, the constant dc flux produced by the synchronous harmonic is not dampened.

The complex geometry of the 45-kW 12/10 machine complicates the analytical estimation of the effective air gap. The presence of several magnets and multiple iron bridges and iron webs together with the nonlinear characteristics of the iron adds to the complexity of the analytical estimations. Such a complex geometry essentially requires FEM modeling in order to accurately estimate the machine parameters.

Experimental validation of the proposed analytical model is somewhat difficult. There is a standard method of measuring the stator leakage inductance with the rotor removed (IEC 60034-4, A39-A40); however, this method in current reading is applicable only for traditional distributed winding machines with $q \geq 1$ and does not accurately take into account the airgap harmonic and tooth-tip leakage inductances of TC-PMSMs. It is practically very difficult to separately measure various inductance components, and therefore, an indirect validation method that only evaluates the total synchronous inductance $L_{\text {sd }}$ is used.

The short-circuit test gives a higher value for the synchronous inductance when compared with the inductance in the nominal point because the stator core is not saturated during the short circuit. Therefore, the short-circuit tests are not feasible for the accurate estimation of synchronous inductances, particularly for high-torque-density machines operating deep in the saturation region. The total synchronous inductance was estimated by the FEM by performing zero-load-angle $\delta_{\text {load }}=0$ simulations using

$$
L_{\mathrm{sd}}=\frac{U_{\mathrm{ph}}-E_{\mathrm{PM}}}{\omega I_{s}} .
$$

During the zero-load-angle simulations, the $U_{\mathrm{ph}}$ was decreased well below the $E_{\mathrm{PM}}$ value or increased in order to reach the nominal current $I_{s}$. The average value of the synchronous inductance between the low and high supply voltage zero-loadangle tests is given in Table III for each machine. The analytically estimated synchronous inductances and the inductances measured by the M1s during the identification runs are also quantified. 
TABLE III

SYNCHRONOUS INDUCTANCES FOR FOUR TC-PMSMs

\begin{tabular}{c|c|c|c|c}
\hline & $26 \mathrm{~kW} 18 / 16$ & $4.7 \mathrm{~kW} 12 / 10$ & $45 \mathrm{~kW} 12 / 10$ & $110 \mathrm{~kW} \mathrm{24/16}$ \\
\hline FEM $\left(\delta_{\text {load }}=0\right)$ & $2.26 \mathrm{mH}$ & $12.7 \mathrm{mH}$ & $10.7 \mathrm{mH}$ & $0.83 \mathrm{mH}$ \\
\hline Measurements $(\mathrm{ID})$ & $2.33 \mathrm{mH}$ & $12.9 \mathrm{mH}$ & $11.2 \mathrm{mH}$ & $0.84 \mathrm{mH}$ \\
\hline Analytical & $2.34 \mathrm{mH}$ & $14.0 \mathrm{mH}$ & $9.33 \mathrm{mH}$ & $0.82 \mathrm{mH}$ \\
\hline
\end{tabular}

The error between the analytically calculated, experimental, and FEM-modeled inductance values is about $17 \%$. The analytical model does not take into account the excessive saturation of the teeth heads and the cross-saturation effects, which can be accurately taken into account only by the FEM [28], [29]. If semimagnetic slot wedges are used, the saturation at the stator teeth heads is decreased, which can be also accurately estimated only by the FEM. However, the analytical model is accurate enough to be used for the performance evaluation of TC-PMSMs at early design stages.

\section{Conclusion}

In this paper, a quantitative and comparative study has been conducted to further develop the analytical calculation technique of different inductance components of TC machines. This paper re-evaluates the applicability of analytical calculation methods for the different inductance components of a TC machine. The approaches to calculate the components of the synchronous inductance have been discussed, and analytical equations have been proposed and validated.

In particular, it has been shown that the performance of TCPMSMs is highly dependent on the leakage inductances, particularly the air-gap harmonic leakage inductance, which often appears to be the dominating component of all the inductance components in TC-PMSMs. Table I could be used by machine designers at an initial design of a TC-PMSM when selecting the winding configuration. The choice should be mainly based on the selection of an appropriate combination of the number of poles, the air-gap leakage factor, and the mutual inductance coefficient. This choice influences the operating frequency of the machine, the rotor losses, the torque production capability, and the field-weakening performance, as well as the short-circuit current and fault-tolerance characteristics of the machine.

To sum up, it is concluded that accurate calculation of the inductances is essential when the performance of a machine is estimated at the early stages of the electrical machine design.

\section{REFERENCES}

[1] A. EL-Refaie, "Fractional-slot concentrated-windings synchronous permanent magnet machines: Opportunities and challenges," IEEE Trans. Ind. Electron., vol. 57, no. 1, pp. 107-121, Jan. 2010.

[2] J. Cros and P. Viarouge, "Synthesis of high performance pm motors with concentrated windings," IEEE Trans. Energy Convers., vol. 17, no. 2, pp. 248-253, Jun. 2002.

[3] F. Magnussen and C. Sadarangani, "Winding factors and joule losses of permanent magnet machines with concentrated windings," in Proc. IEEE IEMDC, 2003, vol. 1, pp. 333-339.

[4] A. El-Refaie, Z. Zhu, T. Jahns, and D. Howe, "Winding inductances of fractional slot surface-mounted permanent magnet brushless machines," in Conf. Rec. IEEE IAS Annu. Meet., 2008, pp. 1-8.

[5] Z. Zhu, D. Howe, and J. Mitchell, "Magnetic field analysis and inductances of brushless dc machines with surface-mounted magnets and non-overlapping stator windings," IEEE Trans. Magn., vol. 31, no. 3, pp. 2115-2118, May 1995.
[6] N. Bianchi, S. Bolognani, M. Pre, and G. Grezzani, "Design considerations for fractional-slot winding configurations of synchronous machines," IEEE Trans. Ind. Appl., vol. 42, no. 4, pp. 997-1006, Jul./Aug. 2006.

[7] J. Pyrhönen, T. Jokinen, and V. Hrabovcová, Design of Rotating Electrical Machines. Hoboken, NJ, USA: Wiley, 2008.

[8] G. Huth, "Permanent-magnet-excited ac servo motors in tooth-coil technology," IEEE Trans. Energy Convers., vol. 20, no. 2, pp. 300-307, Jun. 2005.

[9] E. Schmidt and M. Susic, "Parameter evaluation of permanent magnet synchronous machines with tooth coil windings using the frozen permeabilities method with the finite element analyses," in Proc. IEEE 25th CCECE, 2012, pp. 1-5.

[10] J. Hendershot and T. Miller, Design of Brushless Permanent Magnet Motors. Lebanon, OH, USA: Magna Physics, 1994.

[11] Standart IEC60027-1: Letter Symbols to be Used in Electrical Technology, IEC60027-1, 1995, International Electrotechnical Commission.

[12] R. Dutta, M. F. Rahman, and L. Chong, "Winding inductances of an interior permanent magnet (IPM) machine with fractional slot concentrated winding," IEEE Trans. Magn., vol. 48, no. 12, pp. 4842-4849, Dec. 2012.

[13] P. Ponomarev, P. Lindh, and J. Pyrhönen, "Effect of slot-and-pole combination on the leakage inductance and the performance of tooth-coil permanent-magnet synchronous machines," IEEE Trans. Ind. Electron., vol. 60 , no. 10, pp. 4310-4317, Oct. 2013.

[14] J. Pyrhönen, V. Ruuskanen, J. Nerg, J. Puranen, and H. Jussila, "Permanent-magnet length effects in ac machines," IEEE Trans. Magn., vol. 46, no. 10, pp. 3783-3789, Oct. 2010.

[15] V. Ruuskanen, J. Nerg, M. Niemela, J. Pyrhönen, and H. Polinder, "Effect of radial cooling ducts on the electromagnetic performance of the permanent magnet synchronous generators with double radial forced air cooling for direct-driven wind turbines," IEEE Trans. Magn., vol. 49, no. 6, pp. 2974-2981, Jun. 2013

[16] H. VuXuan, D. Lahaye, H. Polinder, and J. Ferreira, "Improved model for design of permanent magnet machines with concentrated windings," in Proc. IEEE IEMDC, 2011, pp. 948-954.

[17] S. Chevailler, L. Feng, and A. Binder, "Short-circuit faults in distributed and concentrated windings of PM synchronous motors," in Proc. Eur. Conf. Power Electron. Appl., 2007, pp. 1-10.

[18] E. Fornasiero, N. Bianchi, and S. Bolognani, "Slot harmonic impact on rotor losses in fractional-slot permanent-magnet machines," IEEE Trans. Ind. Electron., vol. 59, no. 6, pp. 2557-2564, Jun. 2012.

[19] F. Scuiller, E. Semail, and J.-F. Charpentier, "General modeling of the windings for multi-phase ac machines," Eur. Phys. J. -Appl. Phys., vol. 50, no. 3, pp. 1-15, 2010.

[20] G. Dajaku and D. Gerling, "A novel 12-teeth/10-poles pm machine with flux barriers in stator yoke," in Proc. 20th ICEM, 2012, pp. 36-40.

[21] L. Alberti, E. Fornasiero, and N. Bianchi, "Impact of the rotor yoke geometry on rotor losses in permanent-magnet machines," IEEE Trans. Ind. Appl., vol. 48, no. 1, pp. 98-105, Jan./Feb. 2012.

[22] M. Barcaro and N. Bianchi, "Torque ripple reduction in fractional-slot interior PM machines optimizing the flux-barrier geometries," in Proc. 20th ICEM, 2012, pp. 1496-1502.

[23] R. Richter and R. Brüderlink, Allgemeine Berechnungselemente. Die Gleichstrommaschinen, Ser. Elektrische Maschinen. Basel, Switzerland: Birkhäuser, 1964.

[24] G. Müller, K. Vogt, and B. Ponick, Berechnung elektrischer Maschinen, Ser. Berechnungelektrischer Maschinen, no. Bd. 2. Hoboken, NJ, USA: Wiley, 2008.

[25] J. H. J. Potgieter and M. Kamper, "Evaluation of calculation methods and the effect of end-winding inductance on the performance of non overlap winding PM machines," in Proc. 20th ICEM, 2012, pp. 243-249.

[26] A. I. Voldek, Electrical Machines. Leningrad, Russia: Energy, 1974.

[27] H. Grop, J. Soulard, and H. Persson, "Stator slot leakage in ac-machines equipped with fractional conductor windings," in Proc. ICEMS, 2009, pp. $1-6$.

[28] K. Meessen, P. Thelin, J. Soulard, and E. Lomonova, "Inductance calculations of permanent-magnet synchronous machines including flux change and self- and cross-saturations," IEEE Trans. Magn., vol. 44, no. 10, pp. 2324-2331, Oct. 2008.

[29] B. Stumberger, G. Stumberger, D. Dolinar, A. Hamler, and M. Trlep, "Evaluation of saturation and cross-magnetization effects in interior permanent-magnet synchronous motor," IEEE Trans. Ind. Appl., vol. 39, no. 5, pp. 1264-1271, Sep./Oct. 2003.

Authors' photographs and biographies not available at the time of publication. 